\title{
Serious Gaming - Teaching Science Using Games
}

\author{
Vincent Giasolli,* Robert Giasolli,* Mero Giasolli,* Anthony Girasoli,* Educate for Tomorrow \\ * 361 Opihikao Place, Honolulu, Hawaii 96825, 808-393-3130, www.nanowise.com
}

The best time to plant a tree is 15 years ago, the second best time is today, and so it is with Education.

\section{Introduction}

Everyone is talking about Nanotechnology, but where will we find all the technicians needed to fulfill such a large economic driver? We know that nanotechnology will have a profound impact on our future and that we are at the beginning of a new revolution that will affect nearly every aspect of our lives. We know that our increase in knowledge of science, technology, engineering and mathematics are enabling new products, services, standards of living as well as economic and military security. It appears from national and global testing that few countries are living up to educating primary grade students on the fundamental understanding required to conceptualize atomic science. In addition, it appears that interest and understanding in science decreases as a student moves up through the grades. Before its too late, we need to clearly identify methods to teach atomic understanding to lower and lower grades and provide clear links to the multidisciplinary nature of each lesson.

Have you ever thought about creative ways to teach science? Have you seen the sophisticated games and incredible 3-D animation being produced today? Through games, children are learning about natural scientific properties and the consequences of pushing the boundaries of physical laws while sitting in their room behind a machine. Players must use strategies that include hypothesis and experimentation. Feedback from the game allows the player to determine if their hypothesis was correct. This environment of art and entertainment sounds excitingly similar to the processes we use in research. There is a distinct relationship between gaming and scientific inquiry.

Yet, the gaming industry has no incentive to produce anything except entertainment. Teaching in gaming is cursory at best. Education is incorporated into games in such a way that gamers don't know they are learning anything. Gaming companies hire scientists to insure that the physical world represented will respond correctly to the player's actions, yet learning is not the point of the game.

\section{Pedagogy}

One of the most effective ways to teach is by immersing learners in a rich, authentic environment, as if students were in the field. Through problem based learning (PBL), we present students with realworld problems that are open-ended. Scientific inquiry is vital to the teaching of children in any disciplines related to science, technology, engineering, or mathematics (STEM). Any game that aims at STEM subjects requires PBL and the introduction of scientific inquiry to increase learners' understanding, imagination, and academic performance. 
One primary facet of PBL that we are implementing in the game is the use of "hands on" learning by allowing students to create devices to solve some specific problems. By creating devices, we allow students to have hands on experience with designing, implementing, and evaluating technical solutions. Through this "Virtual Laboratory", we are linking explanation and evidence as well as providing an avenue to qualitative assessment for both the teacher and the student.

PBL requires that students are coached or facilitated through learning. Through the use of embedded assessment, the characters in the game will interact with the student to provide guidance when needed. When a student gets off track, the game will modify its play to bring the student gently back on course. By providing hints and lessons to increase the students understanding of the issue, the game will provide dynamic assistance. Assistance will be provided in such a way that the student can not simply press Enter in order to get the right answer.

Learning freedom is provided through a sandbox mode, allowing students to have fun and learn more by trying different iterations of their devices and compare different outputs. Each new tool created will be added to the student's available tools for solutions later in the game. Each tool can be improved and modified to provide a different solution than originally designed. Sandbox mode will have little assistance and is intended to be used to build and play in an environment unencumbered by a specific purpose.

Lesson plans will also be available for teachers to use with the game. Lessons will use the same characters in the game to teach, providing an interesting lesson plan using characters familiar to the student. Potential challenges within the game will be grouped by subject to allow for better teacher planning. Teachers can use the game in a classroom lesson, preparing students with the needed concepts for later independent game play.

Collaboration is another aspect of PBL, as collaboration leads to providing students with multiple perspectives on how to solve problems. Multiple web sites will be used as a way for learners to collaborate and discover new ideas that are useful in the game. Tools can be created on some web sites that can be imported into the student's tool box for use in solving problems presented during game play. Collaboration with other students across a network of players will allow for discussion and insight common in a research setting. Collaboration with the game's characters, internally within the game, will simulate collaboration with other students when external collaboration is not available.

\section{Epistemologies}

When students complete a device correctly, they are allowed to utilize it in the game. Academic selfefficacy, or the ability of students to truly understand they can affect the world around them, is important for increasing students' academic performance (based on Schunk's and Bandura's research). By using technology to help students' learn through interaction in the game, including the creation of devices and playing mini-games designed as a reward for accomplishing specific tasks, we are increasing the students' academic self-efficacy.

\section{Conclusion}

Through gaming, we make learning fun. By exciting students through the use of technology and utilizing technology correctly in a lesson, we can increase students' academic performance. 